\title{
Ancillary Service Requirement Assessment Indices for the Load Frequency Control in a Restructured Power System with Redox Flow Batteries
}

\begin{abstract}
K. Chandrasekar*, B. Paramasivam* and I.A. Chidambaram ${ }^{\dagger}$
Abstract - This paper proposes various design procedures for computing Power System Ancillary Service Requirement Assessment Indices (PSASRAI) for a Two-Area Thermal Reheat Interconnected Power System (TATRIPS) in a restructured environment. In an interconnected power system, a sudden load perturbation in any area causes the deviation of frequencies of all the areas and also in the tie-line powers. This has to be corrected to ensure the generation and distribution of electric power companies to ensure good quality. A simple Proportional and Integral (PI) controllers have wide usages in controlling the Load Frequency Control (LFC) problems. So the design of the PI controller gains for the restructured power system are obtained using Bacterial Foraging Optimization (BFO) algorithm. From the simulation results, the PSASRAI are calculated based on the settling time and peak over shoot concept of control input deviations of each area for different possible transactions. These Indices are useful for system operator to prepare the power system restoration plans. Moreover, the LFC loop coordinated with Redox Flow Batteries (RFB) has greatly improved the dynamic response and it reduces the control input requirements and to ensure improved PSASRAI, thereby improving the system reliability.
\end{abstract}

Keywords: Load-frequency control, Redox flow batteries, Proportional and integral controller, Power system ancillary service requirement assessment indices

\section{Introduction}

The goal of Load Frequency Control (LFC) is to reestablish primary frequency regulation, return the frequency to its nominal value and minimize unscheduled tie-line power flows between neighboring control area. The operating point of a power system changes with time, and hence the system may experience deviations in nominal frequency and scheduled power exchanges with other areas, which may yield undesirable effects. Due to the sudden load perturbations which continuously disturb the normal operation of a power system, two variables of interest, system frequency and tie-line power exchange, undergo variations. Many control strategies for LFC of power systems have been proposed and investigated by several researchers over the past decades [1]. The variations of system frequency and tie-line power exchange are weighted together by linear combinations with a single variable called Area Control Error (ACE). In the restructure environment, it is generally agreed that the first step is to separate the generation of power from the transmission and distribution companies, thus putting all the generation on the same footing as the Independent Power Producer (IPP)

$\dagger \quad$ Corresponding Author: Dept. of Electrical Engineering, Annamalai University, Annamalainagar, Tamilnadu, India. (driacdm@yahoo.com)

* Dept. of Electrical Engineering, Annamalai University, Annamalainagar, Tamilnadu, India. (\{bpssivam, chandrueeeap $\} @$ gmail.com) Received: February 19, 2015; Accepted: August 8, 2016
$[2,3]$. In an interconnected power system, a sudden load perturbation in any area causes the deviation of frequencies of all the areas and also in the tie-line powers. This has to be corrected to ensure the generation and distribution of electric power companies to ensure good quality. This can be achieved by optimal tuning the Load-Frequency controller gains. Many investigations in the area of LoadFrequency Control (LFC) problem for the interconnected power systems in a deregulated environment have been reported over the past six decades [4-7]. These studies try to modify the conventional LFC system to take into account the effect of bilateral contracts on the dynamics and improve the dynamic and transient response of the system under various operating conditions.

Ancillary services can be defined as a set of activities undertaken by generators, consumers and network service providers and coordinated by the system operator that have to maintain the availability and quality of supply at levels sufficient to validate the assumption of commodity like behavior in the main commercial markets. Ancillary services can be divided into the following three categories and are listed below [8]. (i) Related to spot market implementation, short-term energy-balance and power system frequency. These will be labeled Frequency Control Ancillary Services (FCAS). (ii) Related to aspects of quality of supply other than frequency (primarily voltage magnitude and system security). These will be labeled 
Network Control Ancillary Services (NCAS). (iii) Related to system restoration or re-start following major blackouts. These will be labeled System Restoration Ancillary Services (SRAS). In this paper various methodologies were adopted in computing Power System Ancillary Service Requirement Assessment Indices (PSASRAI) for Two-Area Thermal Reheat Interconnected Power System (TATRIPS) in a restructured environment. With the various PSASRAI like Feasible Assessment Indices (FAI) and Comprehensive Assessment Indices (CAI) gives the remedial measures to be taken like integration of additional spinning reserve, incorporation of effective, intelligent controllers, load shedding etc. In the early stages of power system restoration, the black start units are of the greatest interest because they will produce power for the auxiliaries of the thermal units without black start capabilities. Under this situation a conventional frequency control, i.e., a governor may no longer be able to compensate for sudden load changes due to its slow response. Therefore, in an inter area mode, damping out the critical electromechanical oscillations is to be carried out effectively in the restructured power system. Moreover, the system's control input requirement should be monitored and remedial actions to overcome the control input deviation excursions are more likely to protect the system before it enters an emergency mode of operation. Special attention is therefore given to the behavior of network parameters, control equipments as they affect the voltage and frequency regulation during the restoration process which in turn reflects in PSASRAI. More Recent and powerful evolutionary computational technique Bacterial Foraging Optimization [BFO] [9- 11] is found to be user friendly and is adopted for simultaneous optimization of several parameters for both primary and secondary control loops of the governor. In order to compensate for sudden load changes, an active power source with fast response such as Redox Flow Batteries (RFB) has a wide range of applications such as power quality maintenance of decentralized power supplies. The RFB has effectively short-time overload output and have efficient response characteristics in the particular [12-14]. In this study, BFO algorithm is used to optimize the PI controller gains for LFC of a Two-Area Thermal Reheat Interconnected Power System (TATRIPS) in a restructured environment with and without RFB unit. Various case studies are analyzed to develop PSASRAI namely, Feasible Assessment Index (FAI) and Complete Assessment Index (CAI) which are able to predict the normal operating mode, emergency mode and restorative modes of the power system.

\section{Modeling of a Two-Area Thermal Reheat Interconnected Power System (TATRIPS) in Restructured Scenario}

The deregulated power system consists of GENCOs, DISCOs, and Transmissions Companies (TRANSCOs) and
Independent System Operator (ISO). GENCOs which will compete in a free market to sell the electricity they produce. Mostly the retail customer will continue for some time to buy from the local distribution company and distribution companies have been designated as DISCOs. The entities that will wheel this power between GENCOs and DISCOs have been designated as TRANSCOs. Although it is conceptually clean to have separate functionalities for the GENCOs, TRANSCOs and DISCOs, in reality there will exist companies with combined or partial responsibilities. The LFC in a deregulated electricity market should be designed to consider different types of possible transactions, such as poolco-based transactions, bilateral transactions and a combination of these two [15]. In the new scenario, a DISCO can contract individually with a GENCO for acquiring the power and these transactions will be made under the supervision of ISO. To make the visualization of contracts easier, the concept of "DISCO Participation Matrix" (DPM) is used which essentially provides the information about the participation of a DISCO in contract with a GENCO. In DPM, the number of rows will be equal to the number of GENCOs and the number of columns will be equal to the number of DISCOs in the system. Any entry of this matrix is a fraction of total load power contracted by a DISCO toward a GENCO. In this study two-area interconnected power system in which each area has two GENCOs and two DISCOs. Let $\mathrm{GENCO}_{1}$, $\mathrm{GENCO}_{2}, \mathrm{DISCO}_{1}, \mathrm{DISCO}_{2}$ be in area 1 and $\mathrm{GENCO}_{3}$, $\mathrm{GENCO}_{4}, \mathrm{DISCO}_{3}, \mathrm{DISCO}_{4}$ be in area 2 as shown in Fig. 1. The corresponding DPM is given as follows [4]

$$
D P M=\left[\begin{array}{ccccc}
\multicolumn{5}{c}{D I S C O} \\
c p f_{11} & c p f_{12} & c p f_{13} & c p f_{14} & G \\
c p f_{21} & c p f_{22} & c p f_{23} & c p f_{24} \\
c p f_{31} & c p f_{32} & c p f_{33} & c p f_{34} \\
c p f_{41} & c p f_{42} & c p f_{43} & c p f_{44}
\end{array}\right] \begin{aligned}
& \\
& C \\
& O
\end{aligned}
$$

where $c p f$ represents "Contract Participation Factor" and is like signals that carry information as to which the GENCO has to follow the load demanded by the DISCO. The actual and scheduled steady state power flow through the tie-line are given as

$$
\begin{gathered}
\Delta P_{\text {tie1-2, scheduled }}=\sum_{i=1}^{2} \sum_{j=3}^{4} c p f_{i j} \Delta P_{L_{j}}-\sum_{i=3}^{4} \sum_{j=1}^{2} c p f_{i j} \Delta P_{L_{j}} \\
\Delta P_{\text {tie1-2, actual }}=\left(2 \pi T_{12} / s\right)\left(\Delta F_{1}-\Delta F_{2}\right)
\end{gathered}
$$

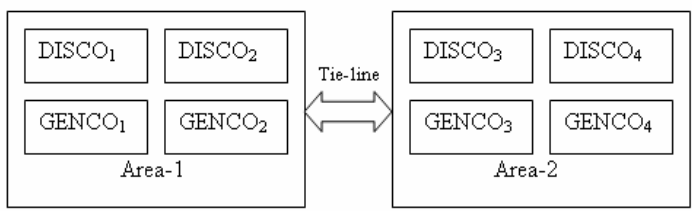

Fig. 1. Schematic diagram of two-area system in restructured environment 
And at any given time, the tie-line power error is defined as

$$
\Delta P_{\text {tiel-2, error }}=\Delta P_{\text {tie1-2, actual }}-\Delta P_{\text {tie1-2, scheduled }}
$$

The error signal is used to generate the respective ACE signals as in the traditional scenario

$$
\begin{aligned}
& A C E_{1}=\beta_{1} \Delta F_{1}+\Delta P_{\text {tie } 1-2, \text { error }} \\
& A C E_{2}=\beta_{2} \Delta F_{2}+\Delta P_{\text {tie } 2-1, \text { error }}
\end{aligned}
$$

For two area system as shown in Fig. 1, the contracted power supplied by $i^{\text {th }}$ GENCO is given as

$$
\Delta P g_{i}=\sum_{j=1}^{D I S C O=4} c p f_{i j} \Delta P L_{j}
$$

Also note that $\triangle P L_{1, L O C}=\triangle P L_{1}+\triangle P L_{2}$ and $\triangle P L_{2, L O C}=$ $\triangle P L_{3}+\triangle P L_{4}$. In the proposed LFC implementation, contracted load is fed forward through the DPM matrix to GENCO set points. The actual loads affect system dynamics via the input $\triangle P L_{, L O C}$ to the power system blocks. Any mismatch between actual and contracted demands will result in frequency deviations that will drive LFC to re dispatch the GENCOs according to ACE participation factors, i.e., $\operatorname{apf}_{11}, \operatorname{apf}_{12}, \operatorname{apf}_{21}$ and $\operatorname{apf}_{22}$. The state space representation of the minimum realization model of ' $N$, area interconnected power system may be expressed as [16].

$$
\begin{aligned}
& \dot{\mathrm{x}}=\mathrm{Ax}+\mathrm{B} u+\Gamma d \\
& y=C x
\end{aligned}
$$

where A is system matrix, $\mathrm{B}$ is the input distribution matrix, $\Gamma$ is the disturbance distribution matrix, $C$ is the control output distribution matrix, $\mathrm{X}$ is the state vector, $u$ is the control vector and $\mathrm{d}$ is the disturbance vector consisting of load changes.

\section{Mathematical Modeling of Redox Flow Batteries}

Electrochemical flow cell systems, also known as Redox flow batteries, convert electrical energy into chemical potential energy by means of a reversible electrochemical reaction between two liquid electrolyte solutions. In contrast with conventional batteries, Redox flow cells store energy in the electrolyte solutions. Therefore, the power and energy ratings are independent, with the storage capacity determined by the quantity of electrolyte used and the power rating determined by the active area of the cell stack. The Redox Flow Batteries are incorporated in the power system to meet the load frequency control problems and to ensure an improved power quality. With the excellent

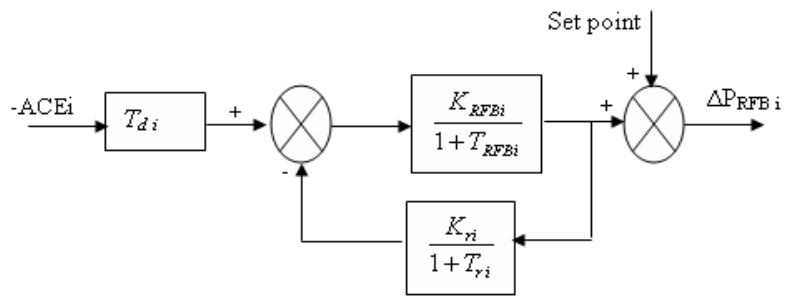

Fig. 2 Redox flow battery system model

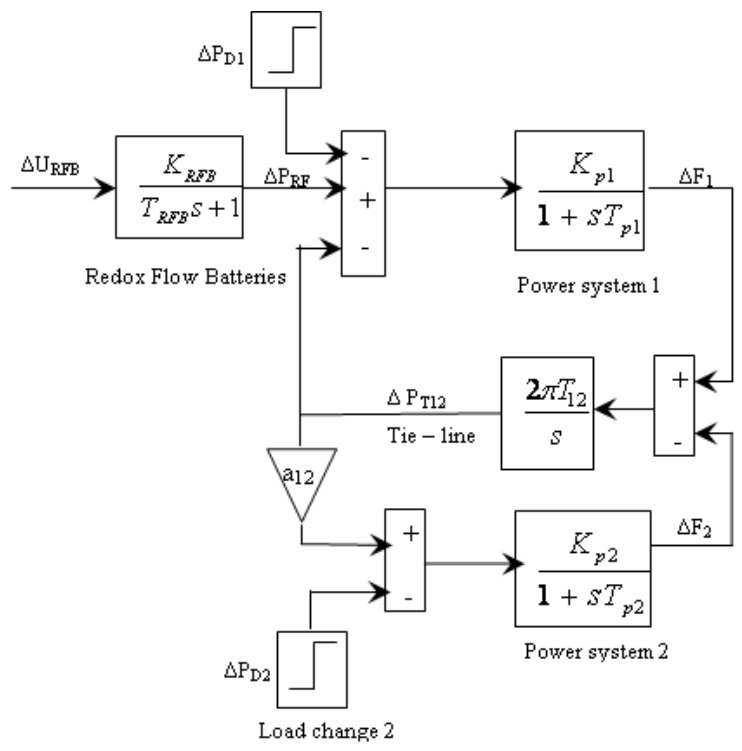

Fig. 3 Linearized reduction model for the control design

short-time overload output and response characteristics possessed by RFB in particular [12-14], the effects of generation control and the absorption of power fluctuation required for power quality maintenance as expected be achieved with the incorporation of RFB unit. The Redox Flow Batteries are capable of ensuring a very fast response and therefore, hunting due to a delay in response does not occur. The block diagram representation of RFB unit is shown in Fig. 2. The Area Control Error (ACE) can be used as the control signal to the RFB.

\subsection{Control design of redox flow battery unit}

The control actions of Redo Flow Batteries (RFB) units are found to be superior to the action of the governor system in terms of the response speed against, the frequency fluctuations [7]. The RFB units are tuned to suppress the peak value of frequency deviations quickly against the sudden load change, subsequently the governor system are actuated for compensating the steady state error of the frequency deviations. Fig. 3 shows the linearized reduction model for the control design of two area interconnected power system with RFB units. The RFB unit is modeled as an active power source to area 1 with a time constant $T_{R F B}$, and gain constant $K_{R F B}$. Assuming the time constants $T_{R F B}$ is regarded as $0 \mathrm{sec}$ for the controller design [7], then the 
state equation of the system represented by Fig. 3 becomes

$$
\left[\begin{array}{c}
\Delta \dot{F}_{1} \\
\Delta \dot{P}_{T 12} \\
\Delta \dot{F}_{2}
\end{array}\right]=\left[\begin{array}{ccc}
-\frac{1}{T_{p 1}} & -\frac{K_{p 1}}{T_{p 1}} & 0 \\
2 \pi T_{12} & 0 & -2 \pi T_{12} \\
0 & \frac{a_{12} k_{p 2}}{T_{p 2}} & -\frac{1}{T_{p 2}}
\end{array}\right]\left[\begin{array}{l}
\Delta F_{1} \\
\Delta P_{T 12} \\
\Delta F_{2}
\end{array}\right]+\left[\begin{array}{l}
\frac{k_{p 1}}{T_{p 1}} \\
0 \\
0
\end{array}\right]\left[\Delta P_{R F B}\right]
$$

The design process starts from the reduction of two area system into one area which represents the Inertia center mode of the overall system. The controller of RFB is designed for the equivalent one area system to reduce the frequency deviation of inertia center mode. The equivalent system is derived by assuming the synchronizing coefficient $\mathrm{T}_{12}$ to be large. From the state equation of $\Delta \dot{P}_{T 12}$ in Eq. (9)

$$
\frac{\Delta \dot{P}_{T 12}}{2 \pi T_{12}}=\Delta F_{1}-\Delta F_{2}
$$

Setting the value of $\mathrm{T}_{12}$ in Eq. (10) to be infinity yields $\Delta \mathrm{F} 1=\Delta \mathrm{F}_{2}$. Next, by multiplying state equation of $\Delta \dot{F}_{1}$ and $\Delta \dot{F}_{2}$ by $\frac{T_{p 1}}{k_{p 1}}$ and $\frac{T_{p 2}}{a_{12} k_{p 2}}$ respectively,

$$
\begin{aligned}
& \frac{T_{p 1}}{k_{p 1}} \Delta \dot{F}_{1}=-\frac{1}{k_{p 1}} \Delta F_{1}-\Delta P_{T 12}+\Delta P_{R F B} \\
& \frac{T_{p 2}}{a_{12} k_{p 2}} \Delta \dot{F}_{2}=\frac{-1}{k_{p 2} a_{12}} \Delta F_{2}+\Delta P_{T 12}
\end{aligned}
$$

By summing Eq. (11) and Eq. (12) and using the above relation $\Delta \mathrm{F}_{1}=\Delta \mathrm{F}_{2}=\Delta \mathrm{F}$

$$
\Delta \dot{F}=\frac{\left(-\frac{1}{k_{p 1}}-\frac{1}{k_{p 2} a_{12}}\right)}{\left(\frac{T_{p 1}}{k_{p 1}}+\frac{T_{p 2}}{k_{p 2} a_{12}}\right)} \Delta F+\frac{1}{\left(\frac{T_{p 1}}{k_{p 1}}+\frac{T_{p 2}}{k_{p 2} a_{12}}\right)} \Delta P_{R F B}+C \Delta P_{D}
$$

Where $\Delta \mathrm{P}_{\mathrm{D}}$ is the load change in this system and the control $\Delta \mathrm{P}_{\mathrm{RFB}}=-\mathrm{K}_{\mathrm{RFB}} \Delta \mathrm{F}$ is applied then.

$$
\Delta F=\frac{C}{s+A+K_{R F B} B} \Delta P_{D}
$$

where $A=\left(-\frac{1}{k_{p 1}}-\frac{1}{k_{p 2} a_{12}}\right) /\left(\frac{T_{p 1}}{k_{p 1}}+\frac{T_{p 2}}{k_{p 2} a_{12}}\right)$

$$
B=\frac{1}{\left[\frac{T_{p 1}}{K_{p 1}}+\frac{T_{p 2}}{K_{p 2} a_{12}}\right]}
$$

where, $\mathrm{C}$ is the proportionality constant between change in frequency and change in load demand. Since the control action of RFB unit is to suppress the deviation of the frequency quickly against the sudden change of $\Delta \mathrm{P}_{\mathrm{D}}$, the percent reduction of the final value after applying a step change $\Delta \mathrm{P}_{\mathrm{D}}$ can be given as a control specification. In Eq. (14) the final values with $K_{R F B}=0$ and with $K_{R F B} \neq 0$ are $\mathrm{C} / \mathrm{A}$ and $\mathrm{C} /\left(\mathrm{A}+\mathrm{K}_{\mathrm{RFB}} \mathrm{B}\right)$ respectively therefore the percentage reduction is represented by

$$
\mathrm{C} /\left(\mathrm{A}+\mathrm{K}_{\mathrm{RFB}} \mathrm{B}\right) /(C / A)=R / 100
$$

For a given R, the controller gain of RFB is calculated as

$$
K_{R F B}=\frac{A}{B R}(100-R)
$$

The linearized model of an interconnected two-area reheat thermal power system in deregulated environment is shown in Fig. 4 after incorporating RFB unit

\section{Design of Decentralized PI Controllers}

The proportional and Integral controller gain values $\left(\mathrm{K}_{\mathrm{pi}}\right.$, $\mathrm{K}_{\mathrm{ii}}$ ) are tuned based on the settling time of the output response of the system (especially the frequency deviation) using Bacterial Foraging Optimization (BFO) technique. The closed loop stability of the system with decentralized PI controllers is assessed using settling time of the system output response $[17,18]$. It is observed that the system whose output response settles fast will have minimum settling time based criterion [19] and can be expressed as

$$
\begin{gathered}
F\left(K_{p}, K_{i}\right)=\min \left(\zeta_{s i}\right) \\
U_{1}=-K_{p} A C E_{1}-K_{I} \int A C E_{1} d t \\
U_{2}=-K_{p} A C E_{2}-K_{I} \int A C E_{2} d t
\end{gathered}
$$

where, $\zeta_{s i}=$ settling time of the frequency deviation of the $i^{\text {th }}$ area under disturbance. The relative simplicity of this controller is a successful approach towards the zero steady state error in the frequency of the system. With these optimized gain values the performance of the system is analyzed and various PSRAI are computed

\section{Bacterial Foraging Optimization Technique}

The BFO method was introduced by Passino [9, 10] motivated by the natural selection which tends to eliminate the animals with poor foraging strategies and favor those having successful foraging strategies. The foraging strategy is governed by four processes, namely Chemotaxis, 
Swarming, Reproduction and Elimination and Dispersal. Chemotaxis process is the characteristics of movement of bacteria in search of food and consists of two processes namely swimming and tumbling. A bacterium is said to be swimming if it moves in a predefined direction, and tumbling if it starts moving in an altogether different direction. To represent a tumble, a unit length random direction $\varphi(j)$ is generated. Let, " $j$ " is the index of chemotactic step, " $k$ " is reproduction step and " $l$ " is the elimination dispersal event. $\theta_{i}(j, k, l)$, is the position of $i^{\text {th }}$ bacteria of $j^{\text {th }}$ chemotactic step $k^{\text {th }}$ reproduction step and $l^{\text {th }}$ elimination dispersal events. The position of the bacteria in the next chemotatic step after a tumble is given by

$$
\theta^{i}(j+1, k, l)=\theta^{i}(j, k, l)+C(i) \varphi(j)
$$

If the health of the bacteria improves after the tumble, the bacteria will continue to swim in the same direction of the specified steps or until the health degrades. Bacteria exhibits swarm behavior, i.e., healthy bacteria tries to attract other bacterium so that together they reach the desired location (solution point) more rapidly. The effect of swarming [10] is to make the bacteria congregate into groups and moves as concentric patterns with high bacterial density. Mathematically swarming behavior can be modeled

$$
\begin{aligned}
& J_{c c}(\theta, P(j, k, l)) \\
& =\sum_{i=1}^{S} J^{i} c c\left(\theta, \theta^{i}(j \cdot k \cdot l)\right) \\
& =\sum_{i=1}^{S}\left[-d_{\text {attract }} \exp \left(-\omega_{\text {attract }}\right) \sum_{m=1}^{p}\left(\theta^{m}-\theta_{m}^{i}\right)^{2}\right] \\
& \quad+\sum_{i=1}^{S}\left[-h_{\text {repelent }} \exp \left(-w_{\text {repelent }}\right) \sum_{m=1}^{p}\left(\theta^{m}-\theta_{m}^{i}\right)^{2}\right]
\end{aligned}
$$

In Reproduction step, population members who have sufficient nutrients will reproduce and the least healthy

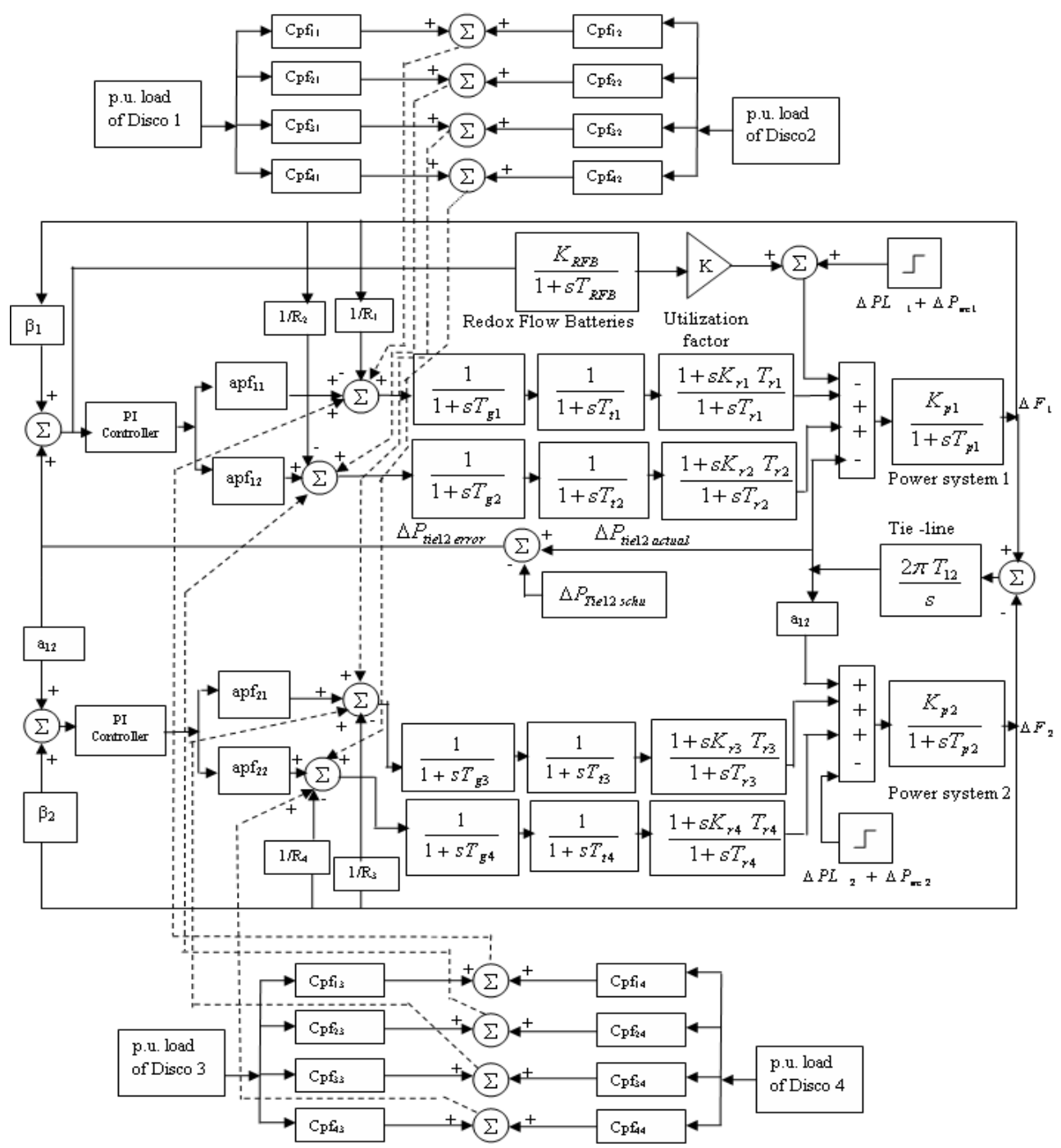

Fig. 4. Linearized models of a Two- Area Thermal Reheat Interconnected Power System (TATRIPS) in a restructured environment with RFB unit 
bacteria will die. The healthier population replaces unhealthy bacteria which get eliminated owing to their poorer foraging abilities. This makes the population of bacteria constant in the evolution process. In this process a sudden unforeseen event may drastically alter the evolution and may cause the elimination and / or dispersion to a new environment. Elimination and dispersal help in reducing the behavior of stagnation i.e., being trapped in a premature solution point or local optima. In the proposed method of proportional plus integral gain $\left(\mathrm{K}_{\mathrm{Pi}}, \mathrm{K}_{\mathrm{Ii}}\right)(\mathrm{i}=1,2)$ scheduling, each bacterium is allowed to take all possible values within the range and the objective function which is represented by Eq. (17) is minimized.

\section{Simulation Results and Observations}

In this study the Two-Area Thermal Reheat Interconnected Restructured Power System is considered and it consists of two GENCOs and two DISCOs in each area as shown in Fig. 4. The nominal parameters are given in Appendix. The optimal solution for the objective function (17) is obtained using the frequency deviations of control areas and tie- line power changes. The gain values of RFB $\left(\mathrm{K}_{\mathrm{RFB}}\right)$ are calculated by using Eq. (16) for the given value of the speed regulation coefficient $(\mathrm{R})$. The gain value is of the RFB is found to be $\mathrm{K}_{\mathrm{RFB}}=0.67$ The Proportional plus Integral controller gains $\left(\mathrm{K}_{\mathrm{p}} \mathrm{K}_{\mathrm{i}}\right)$ are tuned with $\mathrm{BFO}$ algorithm by optimizing the solutions of control inputs for the various case studies as shown in Table 1 and 2

The results are obtained by MATLAB 7.01 software and 100 iterations are chosen for the convergence of the solution using BFO algorithm. These PI controllers are implemented in a Two-Area Thermal Reheat Interconnected restructured Power System with RFB unit considering different utilization of capacity $(\mathrm{K}=0,0.25,0.5,0.75,1.0)$ and for different types of transactions. The corresponding frequency deviations $\Delta f$, tie- line power deviation $\Delta \mathrm{P}_{\text {tie }}$ and control

Table 1 Optimized Controller parameters of the TATRIPS

\begin{tabular}{c|c|c|c|c}
\hline \multirow{2}{*}{ TATRIPS } & \multicolumn{2}{|c|}{$\begin{array}{c}\text { Controller gain } \\
\text { of AREA 1 }\end{array}$} & \multicolumn{2}{c}{$\begin{array}{c}\text { Controller gain } \\
\text { of AREA 2 }\end{array}$} \\
\cline { 2 - 5 } & $\mathrm{K}_{\mathrm{p} 1}$ & $\mathrm{~K}_{\mathrm{i} 1}$ & $\mathrm{~K}_{\mathrm{p} 2}$ & $\mathrm{~K}_{\mathrm{i} 2}$ \\
\hline Case 1 & 0.341 & 0.459 & 0.191 & 0.081 \\
\hline Case 2 & 0.384 & 0.368 & 0.212 & 0.096 \\
\hline Case 3 & 0.428 & 0.396 & 0.236 & 0.127 \\
\hline Case 4 & 0.396 & 0.421 & 0.242 & 0.134 \\
\hline Case 5 & 0.412 & 0.436 & 0.253 & 0.139 \\
\hline Case 6 & 0.316 & 0.513 & 0.121 & 0.196 \\
\hline Case 7 & 0.336 & 0.527 & 0.139 & 0.184 \\
\hline Case 8 & 0.341 & 0.564 & 0.218 & 0.171 \\
\hline Case 9 & 0.357 & 0.568 & 0.247 & 0.195 \\
\hline Case 10 & 0.364 & 0.571 & 0.274 & 0.187 \\
\hline Case 11 & 0.384 & 0.576 & 0.277 & 0.175 \\
\hline Case 12 & 0.401 & 0.584 & 0.279 & 0.205 \\
\hline Case 13 & 0.419 & 0.587 & 0.286 & 0.237 \\
\hline Case 14 & 0.462 & 0.591 & 0.296 & 0.244 \\
\hline
\end{tabular}

Table 2 Optimized Controller parameters of the TATRIPS with RFB unit

\begin{tabular}{c|c|c|c|c}
\hline \multirow{2}{*}{$\begin{array}{c}\text { TATRIPS } \\
\text { with RFB } \\
\text { unit }\end{array}$} & \multicolumn{2}{|c|}{$\begin{array}{c}\text { Controller gain } \\
\text { of AREA 1 }\end{array}$} & \multicolumn{2}{c}{$\begin{array}{c}\text { Controller gain } \\
\text { of AREA 2 }\end{array}$} \\
\cline { 2 - 5 } & $\mathrm{K}_{\mathrm{p} 1}$ & $\mathrm{~K}_{\mathrm{i} 1}$ & $\mathrm{~K}_{\mathrm{p} 2}$ & $\mathrm{~K}_{\mathrm{i} 2}$ \\
\hline Case 1 & 0.214 & 0.498 & 0.101 & 0.094 \\
\hline Case 2 & 0.248 & 0.508 & 0.117 & 0.103 \\
\hline Case 3 & 0.275 & 0.537 & 0.121 & 0.137 \\
\hline Case 4 & 0.289 & 0.553 & 0.138 & 0.202 \\
\hline Case 5 & 0.314 & 0.547 & 0.142 & 0.205 \\
\hline Case 6 & 0.237 & 0.694 & 0.128 & 0.295 \\
\hline Case 7 & 0.279 & 0.705 & 0.158 & 0.308 \\
\hline Case 8 & 0.367 & 0.758 & 0.167 & 0.364 \\
\hline Case 9 & 0.384 & 0.782 & 0.172 & 0.359 \\
\hline Case 10 & 0.388 & 0.794 & 0.219 & 0.363 \\
\hline Case 11 & 0.418 & 0.821 & 0.296 & 0.383 \\
\hline Case 12 & 0.476 & 0.834 & 0.278 & 0.396 \\
\hline Case 13 & 0.526 & 0.805 & 0.265 & 0.427 \\
\hline Case 14 & 0.588 & 0.845 & 0.291 & 0.421 \\
\hline
\end{tabular}

Table 3 Comparison of the system dynamic performance for TATRIPS (Poolco based transactions)

\begin{tabular}{c|c|c|c}
\hline \multicolumn{2}{c|}{ TATRIPS } & Without RFB & With RFB \\
\hline \multirow{2}{*}{$\begin{array}{c}\text { Setting time } \\
\left(\tau_{s}\right) \text { in sec }\end{array}$} & $\Delta \mathrm{F}_{1}$ & 18.14 & 4.561 \\
\cline { 2 - 4 } & $\Delta \mathrm{F}_{2}$ & 17.52 & 4.172 \\
\cline { 2 - 4 } & $\Delta \mathrm{P}_{\text {tie }}$ & 20.13 & 6.027 \\
\hline \multirow{2}{*}{$\begin{array}{c}\text { Peak over/ } \\
\text { under shoot }\end{array}$} & $\Delta \mathrm{F}_{1}$ in Hz & 0.321 & 0.134 \\
\cline { 2 - 4 } & $\Delta \mathrm{F}_{2}$ in Hz & 0.215 & 0.058 \\
\cline { 2 - 4 } & $\Delta \mathrm{P}_{\text {tie }}$ in p.u $\mathrm{MW}$ & 0.082 & 0.023 \\
\hline
\end{tabular}

input deviations $\Delta \mathrm{P}_{\mathrm{c}}$ are obtained with respect to time as shown in figures 5-6. Simulations results reveal that the proposed PI controller for the restructured power system coordinated with RFB units greatly reduces the peak overshoot / undershoot of the frequency deviations and tie- line power flow deviation. And also it reduces the control input requirements and the settling time of the output responses are also reduced considerably is shown in Table 3. Moreover Power System Ancillary Service Requirement Assessment Indices (PSASRAI) namely, Feasible Assessment Indices (FAI) when the system is operating in a normal condition with both units in operation and Comprehensive Assessment Indices (CAI) are one or more unit outage in any area are obtained as discussed.

\subsection{Feasible restoration indices}

\subsubsection{Scenario 1: Poolco based transaction}

Case 1: In the TATRIPS considering both areas have two thermal reheat units. For Poolco based transaction, consider a case where the GENCOs in each area participate equally in LFC. For Poolco based transaction: the load change occurs only in area 1 . It denotes that the load is demanded only by $\mathrm{DISCO}_{1}$ and $\mathrm{DISCO}_{2}$. Let the value of this load demand be 0.1 p.u MW for each of them, i.e., 


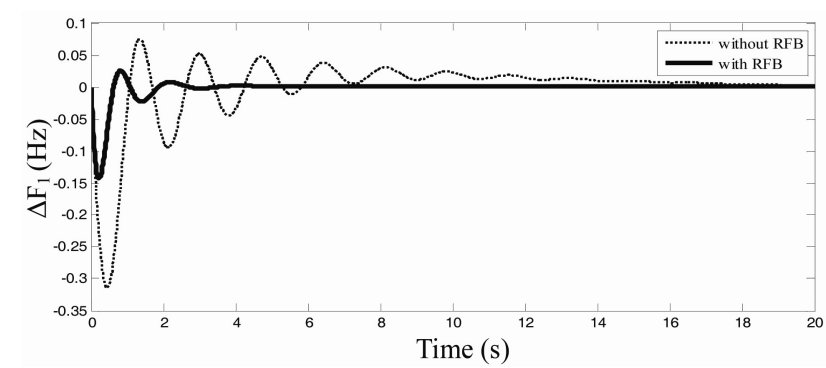

(a) $\Delta \mathrm{F}_{1}(\mathrm{~Hz}) \mathrm{Vs}$ Time (s)

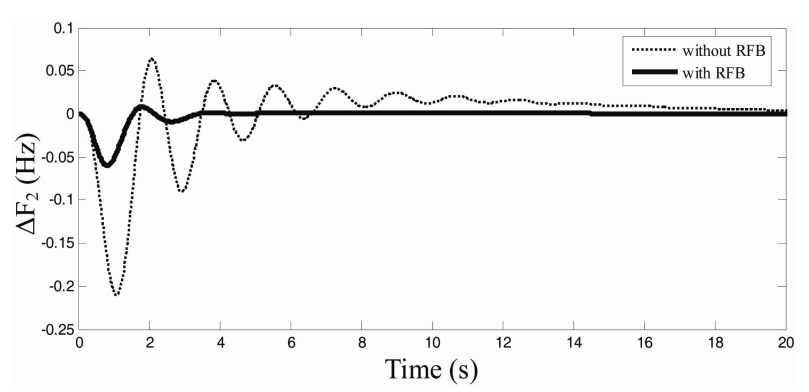

(b) $\Delta \mathrm{F}_{2}(\mathrm{~Hz}) \mathrm{Vs}$ Time (s)

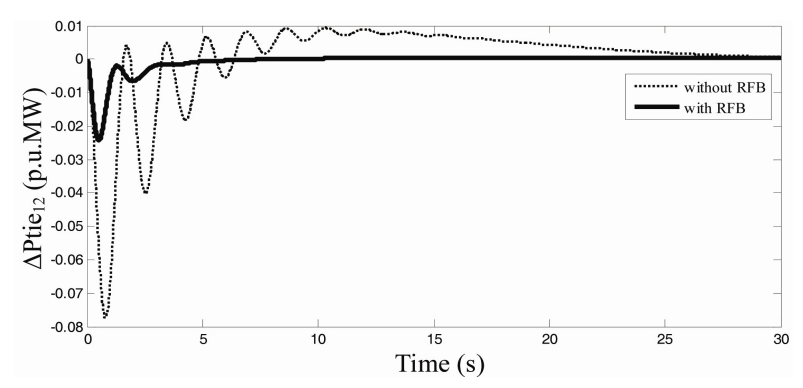

(c) $\Delta$ Ptie $_{12}$ (p.u.MW) Vs Time (s)

$\Delta \mathrm{PL}_{1}=0.1$ p.u MW, $\Delta \mathrm{PL}_{2}=0.1$ p.u MW, $\Delta \mathrm{PL}_{3}=\Delta \mathrm{PL}_{4}=0.0$. DISCO Participation Matrix (DPM) referring to Eq. (1) is considered as [1-4]

$$
D P M=\left[\begin{array}{cccc}
0.5 & 0.5 & 0 & 0 \\
0.5 & 0.5 & 0 & 0 \\
0 & 0 & 0 & 0 \\
0 & 0 & 0 & 0
\end{array}\right]
$$

$\mathrm{DISCO}_{1}$ and $\mathrm{DISCO}_{2}$ demand identically from their local GENCOs, viz., GENCO ${ }_{1}$ and $\mathrm{GENCO}_{2}$. Therefore, $\mathrm{cpf}_{11}=\mathrm{cpf}_{12}=0.5$ and $\mathrm{cpf}_{21}=\mathrm{cpf}_{22}=0.5$. The frequency deviations $(\Delta \mathrm{F})$ of each area, tie-line power deviation $\left(\Delta \mathrm{P}_{\text {tie }}\right)$ and control input requirements deviations $\left(\Delta \mathrm{P}_{\mathrm{c}}\right)$ of both areas are as shown the Fig. 5 . From the Fig. 5 (d) and (e) the corresponding FAI are calculated as follows

Step 1: The Feasible Assessment Index $1\left(\varepsilon_{1}\right)$ is obtained from the ratio between the settling time of the control input deviation $\Delta P_{c 1}\left(\zeta_{s 1}\right)$ response of area 1 and power system time constant $\left(T_{p 1}\right)$ of area 1

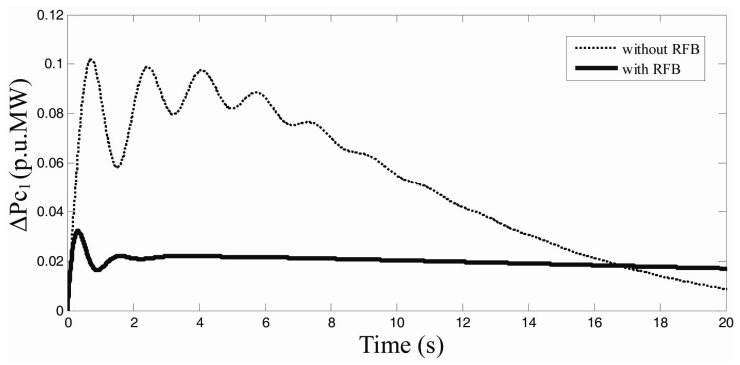

(d) $\Delta \mathrm{Pc}_{1}$ (p.u.MW) Vs Time (s)

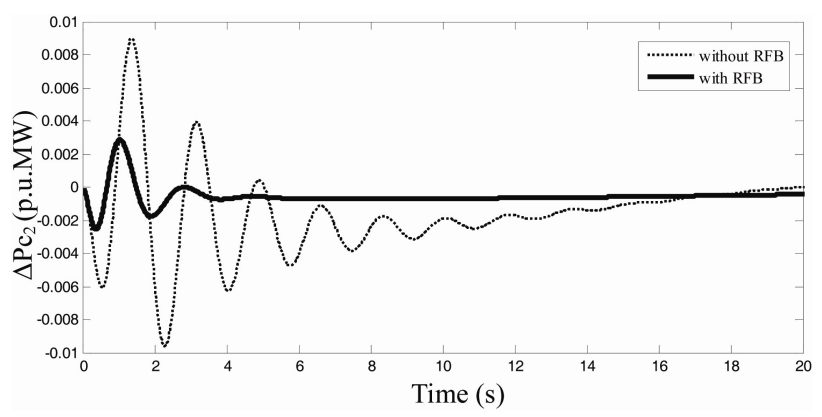

(e) $\Delta \mathrm{Pc}_{2}$ (p.u.MW) Vs Time (s)

Fig. 5. Dynamic responses of the frequency deviations, tieline power deviations and Control input deviations for TATRIPS in the restructured scenario-1 (poolco based transactions)

$$
F R I_{1}=\frac{\Delta P_{c 1}\left(\varsigma_{s 1}\right)}{T_{p 1}}
$$

Step 2: The Feasible Assessment Index $2\left(\varepsilon_{2}\right)$ is obtained from the ratio between the settling time of the control input deviation $\Delta P_{c 2}\left(\zeta_{s 2}\right)$ response of area 2 and power system time constant $\left(T_{p 2}\right)$ of area 2

$$
F R I_{2}=\frac{\Delta P_{c 2}\left(\varsigma_{s 2}\right)}{T_{p 2}}
$$

Step 3: The Feasible Assessment Index $3\left(\varepsilon_{3}\right)$ is obtained from the peak value of the control input deviation $\Delta P_{c 1}\left(\varsigma_{p}\right)$ response of area 1 with respect to the final value $\Delta P_{c 1}\left(\varsigma_{s}\right)$

$$
F R I_{3}=\Delta P_{c 1}\left(\varsigma_{p}\right)-\Delta P_{c 1}\left(\varsigma_{s}\right)
$$

Step 4: The Feasible Assessment Index $4\left(\varepsilon_{4}\right)$ is obtained from the peak value of the control input deviation $\Delta P_{c 2}\left(\varsigma_{p}\right)$ response of area 1 with respect to the final value $\Delta P_{c 2}\left(\varsigma_{s}\right)$

$$
F R I_{4}=\Delta P_{c 2}\left(\varsigma_{p}\right)-\Delta P_{c 2}\left(\varsigma_{s}\right)
$$

Case 2: This case is also referred a Poolco based transaction on TATRIPS where in the GENCOs in each area participate not equally in LFC and load demand is more than the GENCO in area 1 and the load demand 
Table 4. (a) Feasible Assessment Indices (FAI) without and with RFB unit (utilization factor K=1) for TATRIPS

\begin{tabular}{c|c|c|c|c|c|c|c|c|c|c}
\hline \multirow{2}{*}{ TATRIPS } & \multicolumn{4}{|c|}{$\begin{array}{c}\text { Feasible Assessment Indices (FAI) based on control input } \\
\text { deviations }\left(\Delta P_{c}\right) \text { without RFB unit (utilization factor K=0) }\end{array}$} & \multicolumn{4}{c}{$\begin{array}{c}\text { Feasible Assessment Indices (FAI) based on control input } \\
\text { deviations }\left(\Delta P_{c}\right)\end{array}$} \\
& $\varepsilon_{1}$ & $\varepsilon_{2}$ & $\varepsilon_{3}$ & $\varepsilon_{4}$ & $\int P_{\text {without }}$ & $\varepsilon_{1}$ & $\varepsilon_{2}$ & $\varepsilon_{3}$ & $\varepsilon_{4}$ & $\int P_{R F B}$ \\
\hline & 0.975 & 0.886 & 0.133 & 0.027 & 1.056 & 0.813 & 0.724 & 0.098 & 0.008 & 0.526 \\
\hline Case 1 & 1.086 & 0.967 & 0.212 & 0.031 & 1.284 & 0.829 & 0.793 & 0.102 & 0.011 & 0.573 \\
\hline Case 2 & 1.326 & 1.025 & 0.297 & 0.045 & 3.262 & 0.838 & 0.904 & 0.128 & 0.014 & 0.582 \\
\hline Case 3 & 1.185 & 1.322 & 0.224 & 0.067 & 0.782 & 0.934 & 0.939 & 0.131 & 0.018 & 0.594 \\
\hline Case 4 & 1.461 & 1.375 & 0.302 & 0.085 & 3.947 & 1.042 & 1.082 & 0.234 & 0.047 & 0.454 \\
\hline Case 5 & 0.926 & 0.875 & 0.148 & 0.095 & 1.261 & 0.808 & 0.707 & 0.107 & 0.059 & 0.481 \\
\hline Case 6 & 1.126 & 0.916 & 0.216 & 0.098 & 1.452 & 0.904 & 0.901 & 0.147 & 0.075 & 0.525 \\
\hline Case 7 & 1.325 & 1.025 & 0.326 & 0.101 & 3.499 & 0.929 & 0.976 & 0.208 & 0.081 & 0.557 \\
\hline Case 8 & 1.234 & 1.327 & 0.215 & 0.184 & 1.031 & 0.864 & 1.054 & 0.172 & 0.147 & 0.606 \\
\hline Case 9 & 1.376 & 1.345 & 0.341 & 0.196 & 3.269 & 1.008 & 1.109 & 0.274 & 0.161 & 0.623 \\
\hline Case 10 & & & & & & & & & & \\
\hline
\end{tabular}

Table 4. (b) Feasible Assessment Indices (FAI) without and with RFB unit (utilization factor K=0.75) for TATRIPS

\begin{tabular}{|c|c|c|c|c|c|c|c|c|c|c|}
\hline \multirow{2}{*}{ TATRIPS } & \multicolumn{5}{|c|}{$\begin{array}{l}\text { Feasible Assessment Indices (FAI) based on control input } \\
\text { deviations }\left(\Delta P_{c}\right) \text { without RFB unit (utilization factor } \mathrm{K}=0 \text { ) }\end{array}$} & \multicolumn{5}{|c|}{$\begin{array}{l}\text { Feasible Assessment Indices (FAI) based on control input } \\
\text { deviations }\left(\Delta P_{c}\right) \text { with RFB unit (utilization factor } \mathrm{K}=0.75 \text { ) }\end{array}$} \\
\hline & $\varepsilon_{1}$ & $\varepsilon_{2}$ & $\varepsilon_{3}$ & $\varepsilon_{4}$ & $\int \underset{R F B}{P_{\text {without }}}$ & $\varepsilon_{1}$ & $\varepsilon_{2}$ & $\varepsilon_{3}$ & $\varepsilon_{4}$ & $\int P_{R F B}$ \\
\hline Case 1 & 0.975 & 0.886 & 0.133 & 0.027 & 1.056 & 0.874 & 0.801 & 0.104 & 0.012 & 0.458 \\
\hline Case 2 & 1.086 & 0.967 & 0.212 & 0.031 & 1.284 & 0.883 & 0.819 & 0.127 & 0.014 & 0.464 \\
\hline Case 3 & 1.326 & 1.025 & 0.297 & 0.045 & 3.262 & 0.886 & 0.924 & 0.138 & 0.019 & 0.527 \\
\hline Case 4 & 1.185 & 1.322 & 0.224 & 0.067 & 0.782 & 0.972 & 0.984 & 0.142 & 0.021 & 0.559 \\
\hline Case 5 & 1.461 & 1.375 & 0.302 & 0.085 & 3.947 & 1.208 & 1.112 & 0.256 & 0.052 & 0.446 \\
\hline Case 6 & 0.926 & 0.875 & 0.148 & 0.095 & 1.261 & 0.812 & 0.794 & 0.123 & 0.059 & 0.468 \\
\hline Case 7 & 1.126 & 0.916 & 0.216 & 0.098 & 1.452 & 0.948 & 0.891 & 0.163 & 0.076 & 0.527 \\
\hline Case 8 & 1.325 & 1.025 & 0.326 & 0.101 & 3.499 & 0.951 & 0.957 & 0.217 & 0.084 & 0.517 \\
\hline Case 9 & 1.234 & 1.327 & 0.215 & $\begin{array}{l}0.184 \\
\end{array}$ & 1.031 & 0.947 & 1.054 & 0.187 & 0.154 & 0.553 \\
\hline Case 10 & 1.376 & 1.345 & 0.341 & 0.196 & 3.269 & 1.101 & 1.127 & 0.286 & 0.162 & 0.584 \\
\hline
\end{tabular}

Table 4. (c) Feasible Assessment Indices (FAI) without and with RFB unit (utilization factor K=0.5) for TATRIPS

\begin{tabular}{|c|c|c|c|c|c|c|c|c|c|c|}
\hline \multirow{2}{*}{ TATRIPS } & \multicolumn{5}{|c|}{$\begin{array}{l}\text { Feasible Assessment Indices (FAI) based on control input } \\
\text { deviations }\left(\Delta P_{c}\right) \text { without RFB unit (utilization factor } \mathrm{K}=0 \text { ) }\end{array}$} & \multicolumn{5}{|c|}{$\begin{array}{l}\text { Feasible Assessment Indices (FAI) based on control input } \\
\text { deviations }\left(\Delta P_{c}\right) \text { with RFB unit (utilization factor } \mathrm{K}=0.5 \text { ) }\end{array}$} \\
\hline & $\varepsilon_{1}$ & $\varepsilon_{2}$ & $\varepsilon_{3}$ & $\varepsilon_{4}$ & $\int \underset{R F B}{P_{\text {without }}}$ & $\varepsilon_{1}$ & $\varepsilon_{2}$ & $\varepsilon_{3}$ & $\varepsilon_{4}$ & $\int P_{R F B}$ \\
\hline Case 1 & 0.975 & 0.886 & 0.133 & 0.027 & 1.056 & 0.875 & 0.785 & 0.108 & 0.012 & 0.431 \\
\hline Case 2 & 1.086 & 0.967 & 0.212 & 0.031 & 1.284 & 0.892 & 0.814 & 0.131 & 0.021 & 0.445 \\
\hline Case 3 & 1.326 & 1.025 & 0.297 & 0.045 & 3.262 & 0.906 & 0.924 & 0.142 & 0.023 & 0.512 \\
\hline Case 4 & 1.185 & 1.322 & 0.224 & 0.067 & 0.782 & 0.962 & 0.963 & 0.154 & 0.025 & 0.534 \\
\hline Case 5 & 1.461 & 1.375 & 0.302 & 0.085 & 3.947 & 1.182 & 1.104 & 0.268 & 0.058 & 0.423 \\
\hline Case 6 & 0.926 & 0.875 & 0.148 & 0.095 & 1.261 & 0.803 & 0.789 & 0.129 & 0.066 & 0.447 \\
\hline Case 7 & 1.126 & 0.916 & 0.216 & 0.098 & 1.452 & 0.936 & 0.883 & 0.171 & 0.081 & 0.484 \\
\hline Case 8 & 1.325 & 1.025 & 0.326 & 0.101 & 3.499 & 0.945 & 0.965 & 0.235 & 0.089 & 0.465 \\
\hline Case 9 & 1.234 & 1.327 & 0.215 & 0.184 & 1.031 & 0.934 & 1.117 & 0.184 & 0.164 & 0.534 \\
\hline Case 10 & 1.376 & 1.345 & 0.341 & 0.196 & 3.269 & 1.104 & 1.136 & 0.292 & 0.169 & 0.542 \\
\hline
\end{tabular}

Table 4. (d) Feasible Assessment Indices (FAI) without and with RFB unit (utilization factor K=0.25) for TATRIPS

\begin{tabular}{|c|c|c|c|c|c|c|c|c|c|c|}
\hline \multirow{2}{*}{ TATRIPS } & \multicolumn{5}{|c|}{$\begin{array}{l}\text { Feasible Assessment Indices (FAI) based on control input } \\
\text { deviations }\left(\Delta P_{c}\right) \text { without RFB unit (utilization factor } \mathrm{K}=0 \text { ) }\end{array}$} & \multicolumn{5}{|c|}{$\begin{array}{l}\text { Feasible Assessment Indices (FAI) based on control input } \\
\text { deviations }\left(\Delta P_{c}\right) \text { with RFB unit (utilization factor } \mathrm{K}=0.25 \text { ) }\end{array}$} \\
\hline & $\varepsilon_{1}$ & $\varepsilon_{2}$ & $\varepsilon_{3}$ & $\varepsilon_{4}$ & $\int P_{\text {without }}$ & $\varepsilon_{1}$ & $\varepsilon_{2}$ & $\varepsilon_{3}$ & $\varepsilon_{4}$ & $\int P_{R F B}$ \\
\hline Case 1 & 0.975 & 0.886 & 0.133 & 0.027 & 1.056 & 0.861 & 0.796 & 0.112 & 0.018 & 0.398 \\
\hline Case 2 & 1.086 & 0.967 & 0.212 & 0.031 & 1.284 & 0.901 & 0.823 & 0.152 & 0.019 & 0.412 \\
\hline Case 3 & 1.326 & 1.025 & 0.297 & 0.045 & 3.262 & 0.954 & 0.921 & 0.191 & 0.028 & 0.423 \\
\hline Case 4 & 1.185 & 1.322 & 0.224 & 0.067 & 0.782 & 0.965 & 0.964 & 0.154 & 0.042 & 0.521 \\
\hline Case 5 & 1.461 & 1.375 & 0.302 & 0.085 & 3.947 & 1.297 & 1.142 & 0.271 & 0.063 & 0.394 \\
\hline Case 6 & 0.926 & 0.875 & 0.148 & 0.095 & 1.261 & 0.812 & 0.801 & 0.138 & 0.071 & 0.438 \\
\hline Case 7 & 1.126 & 0.916 & 0.216 & 0.098 & 1.452 & 0.952 & 0.883 & 0.187 & 0.089 & 0.453 \\
\hline Case 8 & 1.325 & 1.025 & 0.326 & 0.101 & 3.499 & 0.962 & 0.963 & 0.262 & 0.091 & 0.442 \\
\hline Case 9 & 1.234 & 1.327 & 0.215 & 0.184 & 1.031 & 0.941 & 1.112 & 0.198 & 0.178 & 0.494 \\
\hline Case 10 & 1.376 & 1.345 & 0.341 & 0.196 & 3.269 & 1.202 & 1.162 & 0.296 & 0.183 & 0.493 \\
\hline
\end{tabular}




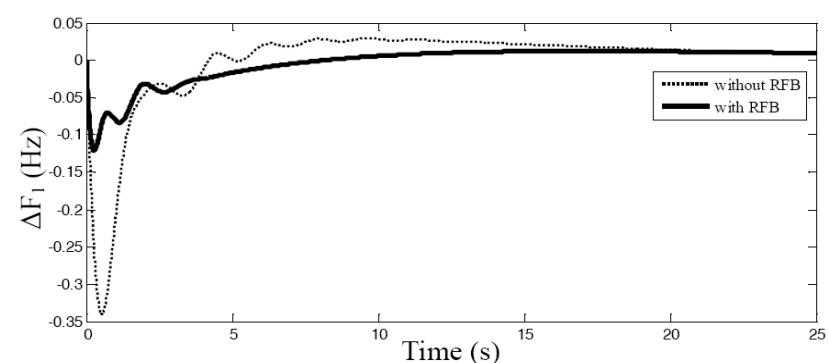

(a) $\Delta \mathrm{F}_{1}(\mathrm{~Hz})$ Vs Time (s)

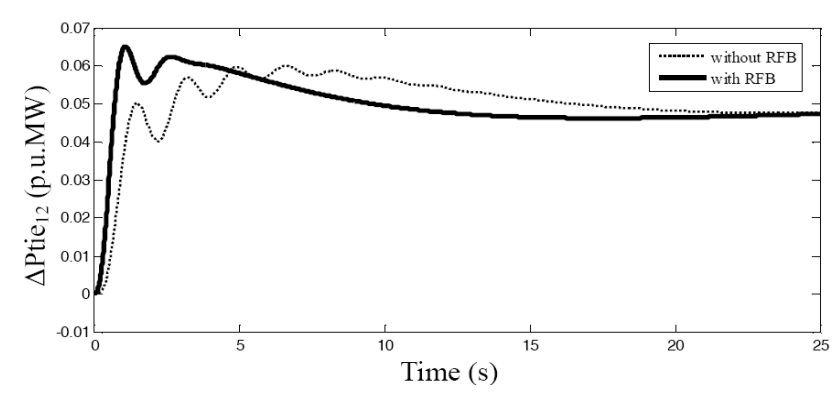

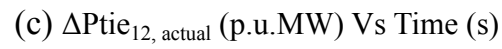

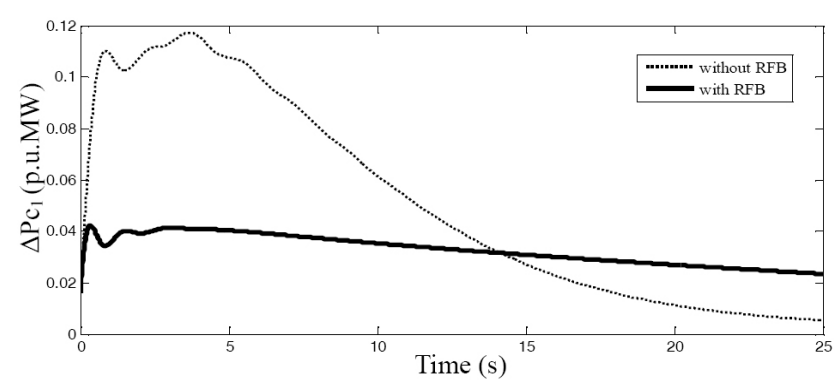

(e) $\Delta \mathrm{Pc}_{1}$ (p.u.MW) Vs Time (s)

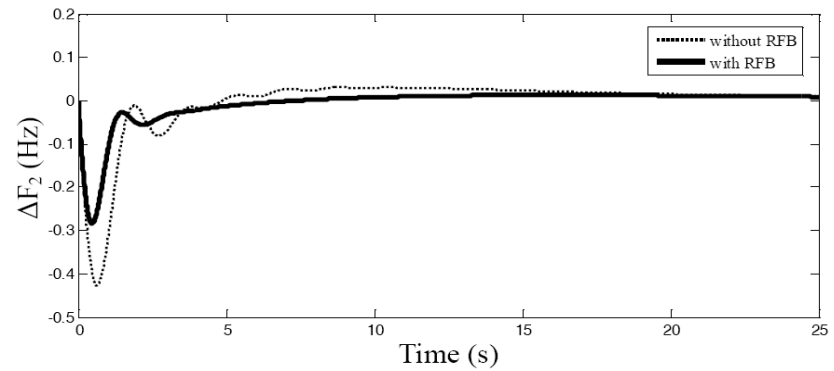

(b) $\Delta F_{2}(\mathrm{~Hz})$ Vs Time (s)

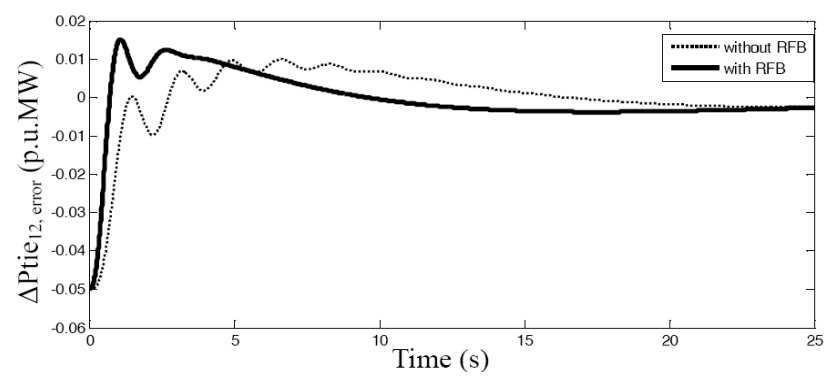

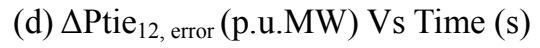

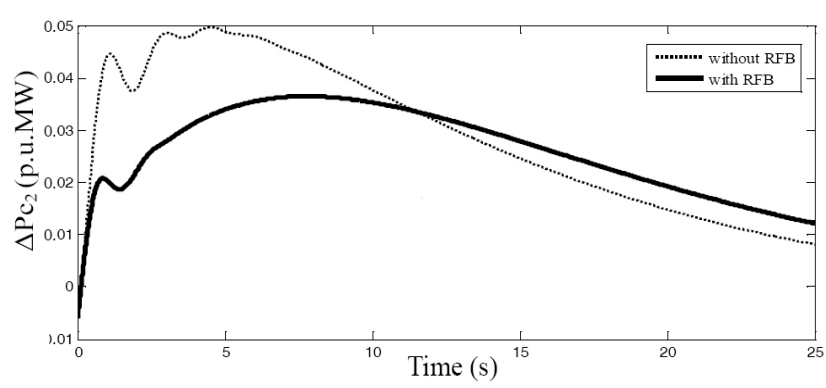

(f) $\Delta \mathrm{Pc}_{2}$ (p.u.MW) Vs Time (s)

Fig. 6. Dynamic responses of the frequency deviations, tie- line power deviations, and Control input deviations for TATRIPS in the restructured scenario-2 (bilateral based transactions)

change occurs only in area 1 . This condition is indicated in the column entries of the DPM matrix and the sum of the column entries is more than unity.

Case 3: It may happen that a DISCO violates a contract by demanding more power than that specified in the contract and this excess power is not contracted to any of the GENCOs. This uncontracted power must be supplied by the GENCOs in the same area to the DISCO. It is represented as a local load of the area, but not as the contract demand. Consider scenario-1 again with a modification that DISCO1 demands 0.1 p.u MW of excess power, i.e., $\Delta \mathrm{P}_{\mathrm{ucl}}=0.1 \mathrm{p} . \mathrm{u} \mathrm{MW}$ and $\Delta \mathrm{P}_{\mathrm{uc} 2}=0.0$ p.u MW.

Case 4: This case is similar to Case 2 to with a modification that $\mathrm{DISCO}_{3}$ demands 0.1 p.u MW of excess power, i.e., $\Delta \mathrm{P}_{\mathrm{uc} 2}=0.1$ p.u MW and., $\Delta \mathrm{P}_{\mathrm{uc} 1}=0$ p.u MW.

Case 5: In this case which is similar to Case 2 with a modification that $\mathrm{DISCO}_{1}$ and $\mathrm{DISCO}_{3}$ demands 0.1 p.u MW of excess power, i.e., $\Delta \mathrm{P}_{\mathrm{ucl}}=0.1$ p.u $\mathrm{MW}$ and $\Delta \mathrm{P}_{\mathrm{uc} 2}=$ 0.1 p.u MW.

\subsubsection{Scenario 2: Bilateral transaction}

Case 6: Here all the DISCOs have contracted with the GENCOs and the following DISCO Participation Matrix (DPM) is considered [4].

$$
D P M=\left[\begin{array}{cccc}
0.4 & 0.25 & 0.2 & 0.4 \\
0.3 & 0.15 & 0.1 & 0.2 \\
0.1 & 0.4 & 0.3 & 0.25 \\
0.2 & 0.2 & 0.4 & 0.15
\end{array}\right]
$$

In this case, the $\mathrm{DISCO}_{1}, \mathrm{DISCO}_{2}, \mathrm{DISCO}_{3}$ and $\mathrm{DISCO}_{4}$, demands 0.15 p.u MW, 0.05 p.u MW, 0.15 p.u MW and 0.05 p.u MW from GENCOs as defined by $c p f$ in the DPM matrix and each GENCO participates in LFC as defined by the following ACE participation factor $\mathrm{apf}_{11}=\mathrm{apf}_{12}=0.5$ and $\operatorname{apf}_{21}=\operatorname{apf}_{22}=0.5$. The dynamic output responses are shown in Fig. 6. The comparative convergence profiles without and with BFO algorithm for TATRIPS in the 
restructured scenario-2 (bilateral based transactions) is shown in Fig. 7. From the figure, it may be concluded that the BFO algorithm approach offers lower values of cost function values $(\mathrm{J})$ and faster converging algorithm and will reduce computational burden as compared with conventional method.

Case 7: For this case also bilateral transaction on TATRIPS is considered with a modification that the GENCOs in each area participate not equally in LFC and load demand is more than the GENCO in both the areas. But it is assumed that the load demand change occurs in both areas and the sum of the column entries of the DPM matrix is more than unity.

Case 8: Considering in the case 7 again with a modification that DISCO 1 demands 0.1 p.u MW of excess power, i.e., $\Delta \mathrm{P}_{\mathrm{uc} 1}=0.1$ p.u. $\mathrm{MW}$ and $\Delta \mathrm{P}_{\mathrm{uc} 2}=0.0$ p.u MW.
Case 9: In the case which similar to case 7 with a modification that $\mathrm{DISCO}_{3}$ demands 0.1 p.u. MW of excess power, i.e., $\Delta \mathrm{P}_{\mathrm{uc} 2}=0.1$ p.u MW.

Case 10: In the case which similar to case 7 with a modification that $\mathrm{DISCO}_{1}$ and $\mathrm{DISCO}_{3}$ demands 0.1 p.u $\mathrm{MW}$ of excess power, i.e., $\Delta \mathrm{P}_{\mathrm{uc} 1}=0.1$ p.u $\mathrm{MW}$ and $\Delta \mathrm{P}_{\mathrm{uc} 2}=$ 0.1 p.u MW. For the Cases 1-10, Feasible Assessment Indices $\varepsilon_{1}, \varepsilon_{2}, \varepsilon_{3}, \varepsilon_{4}$ are calculated using Eq. (23 to 26) as shown in Table 4.

\subsection{Comprehensive assessment indices}

Apart from the normal operating condition of the TATRIPS few other case studies like one unit outage in an area, outage of one distributed generation in an area is considered individually. With the various case studies and

Table 5. (a) Comprehensive Assessment Indices (CAI) without and with RFB unit (utilization factor K=1) for TATRIPS

\begin{tabular}{|c|c|c|c|c|c|c|c|c|c|c|}
\hline \multirow{2}{*}{ TATRIPS } & \multicolumn{5}{|c|}{$\begin{array}{c}\text { Comprehensive Assessment Indices (CAI) based on control input } \\
\left.\text { deviations }\left(\Delta P_{c}\right) \text { without RFB unit } \quad \text { (utilization factor } \mathrm{K}=0\right)\end{array}$} & \multicolumn{5}{|c|}{$\begin{array}{l}\text { Comprehensive Assessment Indices (CAI) based on control } \\
\text { input deviations }\left(\Delta P_{c}\right) \text { with RFB unit (utilization factor } \mathrm{K}=1 \text { ) }\end{array}$} \\
\hline & $\varepsilon_{5}$ & $\varepsilon_{6}$ & $\varepsilon_{7}$ & $\varepsilon_{8}$ & $\int P_{\text {without }}$ & $\varepsilon_{5}$ & $\varepsilon_{6}$ & $\varepsilon_{7}$ & $\varepsilon_{8}$ & $P_{R F B}$ \\
\hline Case 11 & 1.134 & 1.517 & 0.346 & 0.298 & 1.103 & 1.002 & 1.242 & 0.302 & 0.239 & 0.496 \\
\hline Case 12 & 1.524 & 1.524 & 0.383 & 0.341 & 3.194 & 1.088 & 1.353 & 0.321 & 0.301 & 0.593 \\
\hline Case 13 & 1.345 & 1.623 & 0.432 & 0.496 & 1.894 & 1.002 & 1.427 & 0.385 & 0.422 & 0.569 \\
\hline Case 14 & 1.627 & 1.735 & 0.457 & 0.512 & 3.271 & 1.431 & 1.556 & 0.393 & 0.485 & 0.585 \\
\hline
\end{tabular}

Table 5. (b) Comprehensive Assessment Indices (CAI) without and with RFB unit (utilization factor K=0.75) for TATRIPS

\begin{tabular}{|c|c|c|c|c|c|c|c|c|c|c|}
\hline \multirow{2}{*}{ TATRIPS } & \multicolumn{5}{|c|}{$\begin{array}{c}\text { Comprehensive Assessment Indices (CAI) based on control } \\
\text { input deviations }\left(\Delta P_{c}\right) \text { without RFB unit (utilization factor } \mathrm{K}=0 \text { ) }\end{array}$} & \multicolumn{5}{|c|}{$\begin{array}{l}\text { Comprehensive Assessment Indices (CAI) based on control inpu } \\
\left.\text { deviations }\left(\Delta P_{c}\right) \text { with RFB unit (utilization factor } \mathrm{K}=0.75\right)\end{array}$} \\
\hline & $\varepsilon_{5}$ & $\varepsilon_{6}$ & $\varepsilon_{7}$ & $\varepsilon_{8}$ & $\int P_{\text {without }}$ & $\varepsilon_{5}$ & $\varepsilon_{6}$ & $\varepsilon_{7}$ & $\varepsilon_{8}$ & $\int P_{R F B}$ \\
\hline Case 11 & 1.134 & 1.517 & 0.346 & 0.298 & 1.103 & 1.028 & 1.335 & 0.309 & 0.249 & 0.445 \\
\hline Case 12 & 1.524 & 1.524 & 0.383 & 0.341 & 3.194 & 1.108 & 1.414 & 0.324 & 0.308 & 0.523 \\
\hline Case 13 & 1.345 & 1.623 & 0.432 & 0.496 & 1.894 & 1.013 & 1.501 & 0.387 & 0.413 & 0.536 \\
\hline Case 14 & 1.627 & 1.735 & 0.457 & 0.512 & 3.271 & 1.442 & 1.606 & 0.401 & 0.489 & 0.545 \\
\hline
\end{tabular}

Table 5. (c) Comprehensive Assessment Indices (CAI) without and with RFB unit (utilization factor K=0.5) for TATRIPS

\begin{tabular}{|c|c|c|c|c|c|c|c|c|c|c|}
\hline \multirow{2}{*}{ TATRIPS } & \multicolumn{5}{|c|}{$\begin{array}{l}\text { Comprehensive Assessment Indices (CAI) based on control input } \\
\left.\text { deviations }\left(\Delta P_{c}\right) \quad \text { without RFB unit (utilization factor } \mathrm{K}=0\right)\end{array}$} & \multicolumn{5}{|c|}{$\begin{array}{c}\text { Comprehensive Assessment Indices (CAI) based on control input } \\
\left.\text { deviations }\left(\Delta P_{c}\right) \text { with RFB unit (utilization factor } \mathrm{K}=0.5\right)\end{array}$} \\
\hline & $\varepsilon_{5}$ & $\varepsilon_{6}$ & $\varepsilon_{7}$ & $\varepsilon_{8}$ & $\int P_{\text {without }}$ & $\varepsilon_{5}$ & $\varepsilon_{6}$ & $\varepsilon_{7}$ & $\varepsilon_{8}$ & $\int P_{R F B}$ \\
\hline Case 11 & 1.134 & 1.517 & 0.346 & 0.298 & 1.103 & 1.054 & 1.323 & 0.317 & 0.252 & 0.383 \\
\hline Case 12 & 1.524 & 1.524 & 0.383 & 0.341 & 3.194 & 1.198 & 1.434 & 0.324 & 0.314 & 0.447 \\
\hline Case 13 & 1.345 & 1.623 & 0.432 & 0.496 & 1.894 & 1.087 & 1.545 & 0.401 & 0.428 & 0.325 \\
\hline Case 14 & 1.627 & 1.735 & 0.457 & 0.512 & 3.271 & 1.484 & 1.614 & 0.408 & 0.497 & 0.464 \\
\hline
\end{tabular}

Table 5. (d) Comprehensive Assessment Indices (CAI) without and with RFB unit (utilization factor K=0.25) for TATRIPS

\begin{tabular}{|c|c|c|c|c|c|c|c|c|c|c|}
\hline \multirow{2}{*}{ TATRIPS } & \multicolumn{5}{|c|}{$\begin{array}{l}\text { Comprehensive Assessment Indices (CAI) based on control } \\
\text { input deviations }\left(\Delta P_{c}\right) \text { without RFB unit (utilization factor } \mathrm{K}=0 \text { ) }\end{array}$} & \multicolumn{5}{|c|}{$\begin{array}{l}\text { Comprehensive Assessment Indices (CAI) based on control input } \\
\left.\text { deviations }\left(\Delta P_{c}\right) \text { with RFB unit (utilization factor } \mathrm{K}=0.25\right)\end{array}$} \\
\hline & $\varepsilon_{5}$ & $\varepsilon_{6}$ & $\varepsilon_{7}$ & $\varepsilon_{8}$ & $\int P_{\text {without }}$ & $\varepsilon_{5}$ & $\varepsilon_{6}$ & $\varepsilon_{7}$ & $\varepsilon_{8}$ & $\int P_{R F B}$ \\
\hline Case 11 & 1.134 & 1.517 & 0.346 & 0.298 & 1.103 & 1.075 & 1.212 & 0.325 & 0.262 & 0.342 \\
\hline Case 12 & 1.524 & 1.524 & 0.383 & 0.341 & 3.194 & 1.142 & 1.298 & 0.331 & 0.313 & 0.412 \\
\hline Case 13 & 1.345 & 1.623 & 0.432 & 0.496 & 1.894 & 1.152 & 1.456 & 0.404 & 0.435 & 0.435 \\
\hline Case 14 & 1.627 & 1.735 & 0.457 & 0.512 & 3.271 & 1.348 & 1.534 & 0.419 & 0.502 & 0.442 \\
\hline
\end{tabular}


based on their optimal gains the corresponding CAI is obtained as follows.

Case 11: In the TATRIPS considering all the DISCOs have contracted with the GENCOs but $\mathrm{GENCO}_{4}$ is outage in the area-2. In this case, the $\mathrm{DISCO}_{1}, \mathrm{DISCO}_{2}, \mathrm{DISCO}_{3}$ and $\mathrm{DISCO}_{4}$, demands 0.15 p.u MW, 0.05 p.u MW, 0.15 pu.MW and 0.05 pu.MW from GENCOs as defined by $c p f$ in the DPM matrix (24). The output $\mathrm{GENCO}_{4}=0.0$ p.u MW.

Case 12: Consider in this case which is same as Case 11 but $\mathrm{DISCO}_{1}$ demands 0.1 p.u MW of excess power, i.e., $\Delta \mathrm{P}_{\mathrm{uc} 1}=0.1$ p.u.MW and $\Delta \mathrm{P}_{\mathrm{uc} 2}=0.0$ p.u MW. The total load in area $1=$ Load of DISCO $_{1}+$ Load of DISCO $_{2}=\Delta \mathrm{PL}_{1}+$ $\Delta \mathrm{P}_{\mathrm{ucl}}+\Delta \mathrm{PL}_{2}=0.15+0.1+0.05=0.3$ p.u MW and total load in area $2=$ Load of $\mathrm{DISCO}_{3}+\mathrm{Load}$ of $\mathrm{DISCO}_{4}=\Delta \mathrm{PL}_{3}+$ $\Delta \mathrm{PL}_{4}=0.15+0.05=0.2$ p.u MW.

Case 13: This case is same as Case 11 with a modifycation that $\mathrm{DISCO}_{3}$ demands 0.1 p.u MW of excess power i.e., $\Delta \mathrm{P}_{\mathrm{uc} 2}=0.1$ p.u MW. The total load in area $1=$ Load of $\mathrm{DISCO}_{1}+$ Load of $\mathrm{DISCO}_{2}=\Delta \mathrm{PL}_{3}+\Delta \mathrm{PL}_{4}=0.15+0.05=0.2$ p.u MW and total demand in area $2=$ Load of $\mathrm{DISCO}_{3}+$ Load of $\mathrm{DISCO}_{4}=\Delta \mathrm{PL}_{3}+\Delta \mathrm{PL}_{4}+\Delta \mathrm{P}_{\mathrm{uc} 2}=0.15+0.05+0.1=0.3$ p.u MW.

Case 14: In this case which is similar to Case 11 with a modification that $\mathrm{DISCO}_{1}$ and $\mathrm{DISCO}_{3}$ demands 0.1 p.u MW of excess power, i.e., $\Delta \mathrm{P}_{\mathrm{uc} 1}=0.1$ p.u.MW and $\Delta \mathrm{P}_{\mathrm{uc} 2}=$ 0.1 p.u MW. The total load in area $1=$ Load of $\mathrm{DISCO}_{1}+$ Load of $\mathrm{DISCO}_{2}=\Delta \mathrm{PL}_{1}+\Delta \mathrm{P}_{\mathrm{uc} 1}+\Delta \mathrm{PL}_{2}=0.15+0.1+0.05=$ 0.3 p.u MW and total load in area $2=$ Load of $\mathrm{DISCO}_{3}+$ Load of $\mathrm{DISCO}_{4}=\Delta \mathrm{PL}_{3}+\Delta \mathrm{P}_{\mathrm{uc} 2}+\Delta \mathrm{PL}_{4}=0.15+0.1+0.05$ $=0.3$ p.u MW. For the Case 11-14, the corresponding Assessment Indices are referred as Comprehensive Assessment Indices $\varepsilon_{5}, \varepsilon_{6}, \varepsilon_{7}, \varepsilon_{8}$ are obtained using Eq. (23 to 26) as are tabulated in Table 5 .

\subsection{Power System Ancillary Service Requirement Assessment Indices (PSASRAI)}

\subsubsection{Based on Settling Time}

(i) If $\varepsilon_{1}, \varepsilon_{2}, \varepsilon_{5}, \varepsilon_{6} \geq 1$ then the integral controller gain of each control area has to be increased, causing the speed changer valve to open up widely. Thus the speed- changer position attains a constant value only when the frequency error is reduced to zero.

(ii) If $1.0<\varepsilon_{1}, \varepsilon_{2}, \varepsilon_{5}, \varepsilon_{6} \leq 1.5$ then more amount of distributed generation requirement is needed. Energy storage is an attractive option to augment demand side management implementation by ensuring the Ancillary Services to the power system.

(iii) If $\varepsilon_{1}, \varepsilon_{2}, \varepsilon_{5}, \varepsilon_{6} \geq 1.5$ then the system is vulnerable and the system becomes unstable and may even result to blackouts.

\subsubsection{Based on peak undershoot}

(i) If $0.15 \leq \varepsilon_{3}, \varepsilon_{4}, \varepsilon_{7}, \varepsilon_{8}<0.2$ then Energy Storage

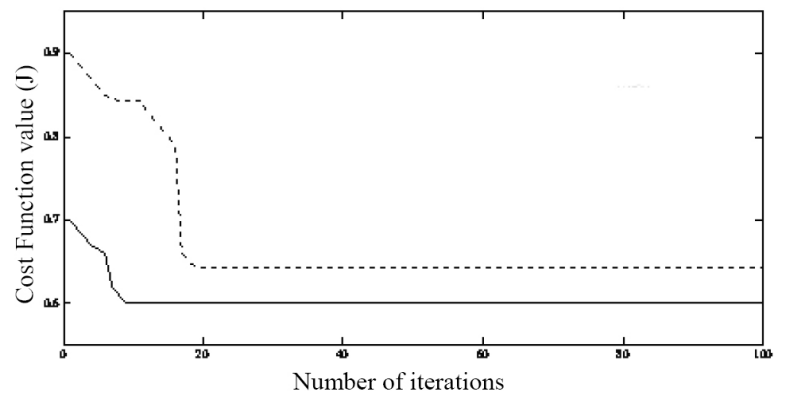

Fig. 7. Convergence profiles for TATRIPS in the restructured scenario-2 (bilateral based transactions) (solid lineusing BFO algorithm and dashed line conventional method)

Systems (ESS) for LFC are required as the conventional load-frequency controller may no longer be able to attenuate the large frequency oscillation due to the slow response of the governor for unpredictable load variations. A fast-acting energy storage system in addition to the kinetic energy of the generator rotors is advisable to damp out the frequency oscillations.

(ii) If $0.2 \leq \varepsilon_{3}, \varepsilon_{4}, \varepsilon_{7}, \varepsilon_{8}<0.3$ then more amount of distribution generation requirement is required or Energy Storage Systems (ESS) coordinated control with the FCTS devices are required for the improvement relatively stability of the power system in the LFC application and the load shedding is also preferable.

(iii) If $\varepsilon_{3}, \varepsilon_{4}, \varepsilon_{7}, \varepsilon_{8}>0.3$ then the system is vulnerable and the system becomes unstable and may result to blackout.

\section{Conclusions}

This paper proposes the design of various Power System Ancillary Service Requirement Assessment Indices (PSASRAI) which highlights the necessary requirements to be adopted in minimizing the frequency deviations, tie-line power deviation in a two-area Thermal reheat interconnected restructured power system in a faster manner to ensure the reliable operation of the power system. The PI controllers are designed using BFO algorithm and implemented in a TATRIPS without and with RFB unit. This BFO Algorithm was employed to achieve the optimal parameters of gain values of the various combined control strategies as BFO algorithm is easy to implement without additional computational complexity, with quite promising results and ability to jump out the local optima. Moreover, Power flow control of RFB unit is also found to be efficient and effective for improving the dynamic performance of load frequency control of the interconnected power system than that of the system without RFB unit. From the simulated results it is observed that the restoration indices calculated for the TATRIPS with RFB unit indicates that more sophisticated 
control for a better restoration of the power system output responses and to ensure improved Power System Ancillary Service Requirement Assessment Indices (PSASRAI) in order to provide a good margin of stability than that of the TATRIPS without RFB unit.

\section{References}

[1] H. Shayeghi, H. A. Shayanfar and A. Jalili, "Load frequency control strategies: A state-of-the-art survey for the researcher", Energy Conversion and Management, Vol. 50, Issue 2, pp. 344-353, 2009.

[2] Mukta, Balwinder Singh Surjan, "Load Frequency Control of Interconnected Power System in Deregulated Environment: A Literature Review", International Journal of Engineering and Advanced: Vol. 2, Issue-3, pp. 435-441, 2013.

[3] Elyas Rakhshani, and Javad Sadesh "Practical viewpoints on load frequency control problem in a deregulated power system", Energy Conversion and Management, Vol. 51, No. 5, pp. 1148 -1156, 2010.

[4] V. Donde, M. A. Pai, and I. A. Hiskens, "Simulation and optimization in an AGC system after deregulation", IEEE Transactions on Power Systems, Vol. 16, No. 3, pp. 481-489, 2001.

[5] Tan Wen, Zhang. H, Yu.M, "Decentralized load frequency control in deregulated environments", Electrical Power and Energy Systems, Vol. 41, pp. 16-26, 2012.

[6] Bhatt. P, Roy. R, Ghoshal. SP, "Optimized multi area AGC simulation in restructured power systems", Electrical Power and Energy Systems, Vol. 32, pp. 311-322, 2010.

[7] I. A. Chidambaram and B. Paramasivam, "Optimized Load- Frequency Simulation in Restructured Power System with Redox Flow Batteries and Interline Power Flow Controller", International Journal of Electrical Power and Energy Systems, Vol. 50, pp. 924, Feb 2013.

[8] J. O. P. Rahi, Harish Kumar Thakur, Abhash Kumar Singh, Shashi Kant Gupta, "Ancillary Services in Restructured Environment of Power System", International Journal of Innovative Technology and Research, Vol. 1, Issue No. 3, pp.218-225, 2013.

[9] K. M. Passino, "Biomimicry of bacterial foraging for distributed optimization and control", IEEE Control Syst Magazine, Vol. 22, No. 3, pp. 52-67, 2002.

[10] Janardan Nanda, Mishra.S., Lalit Chandra Saikia, "Maiden Application of Bacterial Foraging-Based optimization technique in multi-area Automatic Generation Control", IEEE Transaction on Power System, Vol. 24, No. 2, pp. 602-609, 2009.

[11] M. Peer Mohamed, E. A. Mohamed Ali, I. Bala Kumar, "BFOA Based Tuning of PID Controller For
A Load Frequency Control In Four Area Power System", International Journal of Communications and Engineering,, Vol. 3, No.3, Issue: 02, pp/45-52. 2012.

[12] N. Tokuda, "Development of a Redox Flow Battery System", Engineering conf.co, IECEC-98-1074, August, 1998.

[13] K. Enomoto, T. Sasaki, T. Shigematsu and H. Deguchi, "Evaluation study about Redox Flow Battery Response and its Modeling", IEEJ Transactions on Power Engineering, Vol. 122-13, No. 4, pp 554-560, 2002.

[14] Tetsuo Sasaki, Toshihisa Kadoya, and Kazuhiro Enomoto, "Study on Load frequency Control using Redox Flow Batteries", IEEE Transactions on Power Systems, Vol. 19, No. 1, pp. 660-667, 2004.

[15] R. D. Christie and A. Bose, "Load frequency control issues in power system operations after deregulation," IEEE Transactions on Power Systems, Vol. 11, No. 3 pp. 1191-1200, 1996.

[16] I.A. Chidambaram and S. Velusami, "Design of decentralized biased controllers for load-frequency control of interconnected power systems", Electric Power Components and Systems, Vol. 33, No. 12, pp.1313-1331, 2005.

[17] Surya Prakash, S.K.Sinha, "Artificial Intelligent and PI in Load Frequency Control of Interconnected Power system", International Journal of Computer Science \& Emerging Technologies, Vol. 1, Issue 4, pp.377-384, December 2010,

[18] Tushar Jain , M.J. Nigam, "Optimization of Pd-Pi controller using Swarm Intelligence", International journal of Computational Cognition, Vol. 6, No. 4, pp.55-59, 2008

[19] K.Sabani, A. Sharifi, M. Aliyari sh, M.Teshnehlab, M. Aliasghary, "Load Frequency Control in Interconnected Power system using multi-objective PID controller", Journal of Applied Sciences, Vol. 8, No. 20, pp. 3676-3682, 2010.

\section{Appendix}

\section{A.1 Data for Thermal Reheat Power System [16]}

Rating of each area $=2000 \mathrm{MW}$, Base power $=2000$ MVA, $\mathrm{f}^{\mathrm{o}}=60 \mathrm{~Hz}, \mathrm{R}_{1}=\mathrm{R}_{2}=\mathrm{R}_{3}=\mathrm{R}_{4}=2.4 \mathrm{~Hz} /$ p.u.MW, $\mathrm{T}_{\mathrm{g} 1}=\mathrm{T}_{\mathrm{g} 2}=\mathrm{T}_{\mathrm{g} 3}=\mathrm{T}_{\mathrm{g} 4}=0.08 \mathrm{~s}, \mathrm{~T}_{\mathrm{r} 1}=\mathrm{T}_{\mathrm{r} 2}=\mathrm{T}_{\mathrm{r} 1}=\mathrm{T}_{\mathrm{r} 2}=10 \mathrm{~s}$, $\mathrm{T}_{\mathrm{t} 1}=\mathrm{T}_{\mathrm{t} 2}=\mathrm{T}_{\mathrm{t} 3}=\mathrm{T}_{\mathrm{t} 4}=0.3 \mathrm{~s}, \mathrm{~K}_{\mathrm{p} 1}=\mathrm{K}_{\mathrm{p} 2}=120 \mathrm{~Hz} /$ p.u.MW, $\mathrm{T}_{\mathrm{p} 1}=\mathrm{T}_{\mathrm{p} 2}=20 \mathrm{~s}, \beta_{1}=\beta_{2}=0.425$ p.u.MW $/ \mathrm{Hz}, \mathrm{K}_{\mathrm{r} 1}=\mathrm{K}_{\mathrm{r} 2}=$ $\mathrm{K}_{\mathrm{r} 3}=\mathrm{K}_{\mathrm{r} 4}=0.5,2 \pi T_{12}=0.545$ p.u.MW $/ \mathrm{Hz}, \mathrm{a}_{12}=-1$.

A.2 Data for the RFB unit [14]

$\mathrm{T}_{\mathrm{RFB}}=0, \mathrm{~T}_{\mathrm{di}}=0, \mathrm{~T}_{\mathrm{ri}}=0$ 


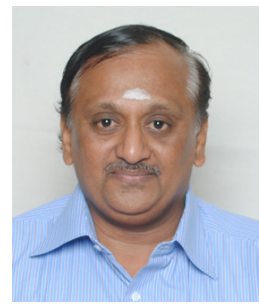

I. A. Chidambaram (1966) received Bachelor of Engineering in Electrical and Electronics Engineering (1987), Master of Engineering in Power System Engineering (1992) and Ph.D in Electrical Engineering (2007) from Annamalai University, Annamalainagar. During 1988 - 1993 he was working as Lecturer in the Department of Electrical Engineering, Annamalai University and from 2007 he is working as Professor in the Department of Electrical Engineering, Annamalai University, Annamalainagar. He is a member of ISTE and ISCA. He is an Associate Member in the IET and Fellow in the Institute of Engineers (India). He has produced $7 \mathrm{PhD}$ Scholars and has around 55 International Journal publications to his credit. His research interests are in Power Systems operation and Restructuring, Electrical Measurements and Controls.driacdm@yahoo.com

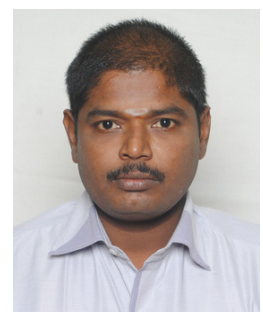

B. Paramasivam (1976) received Bachelor of Engineering in Electrical and Electronics Engineering (2002), Master of Engineering in Power System Engineering (2008) and Ph.D in Electrical Engineering (2013) from Annamalai University. He is working as Assistant Professor in the Department of Electrical Engineering, Annamalai University, Annamalainagar-608002, Tamilnadu, India. His research interests are in Power System Operation and Restructuring, Control Systems, Electrical Measurements.

bpssivam@gmail.com

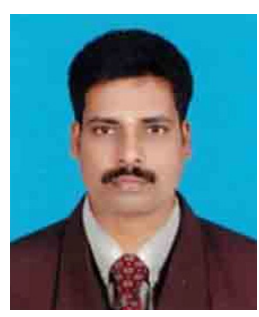

K.Chandrasekar (1976) received Bachelor of Engineering in Electrical and Electronics Engineering (2002), Master of Engineering in Power System Engineering (2008) and he is working as Assistant Professor in the Department of Electrical Engineering, Annamalai University, Annamalainagar608002, Tamilnadu, India. He is currently pursuing Ph.D degree in Electrical Engineering at Annamalai University, Annamalainagar. His research interests are in Power System Operation and Control, Electrical and Electronic Measurements. chandrueeeap@gmail.com 